\title{
Torsade de pointes ventricular tachycardia in a newborn infant
}

\author{
JOHN P. FINLEY, DOROTHY J. RADFORD, AND ROBERT M. FREEDOM
}

From the Division of Cardiology, Department of Paediatrics, Department of Pathology, The Hospital for Sick Children, Toronto, and Departments of Paediatrics and Pathology, The University of Toronto, Ontario, Canada

SUMMARY A case of paroxysmal ventricular tachycardia of torsade de pointes variety occurring in a newborn infant is described. A rare problem in the newborn, ventricular tachycardia has been associated with congenital heart disease, electrolyte abnormality, and cardiac tumour. In this case, the association was with myocarditis. The arrhythmia was refractory to treatment, and the infant died.

Ventricular tachycardia is unusual in children and even rarer in neonates (Addy and Littlewood, 1969; DeGuzman and Silver, 1970; Eibschitz et al., 1975; Hernandez et al., 1975). Torsade de pointes, a variant of ventricular tachycardia, is also rare. It is recognisable by a regularly changing axis in the ventricular complexes of the electrocardiogram (Krikler and Curry, 1976). We present here a case of paroxysmal ventricular tachycardia of torsade de pointes variety, which occurred in a newborn infant with myocarditis and caused a rare and difficult management problem. We are not aware of a report of a similar case.

\section{Case report}

A male infant was born of a 21-year-old primigravida after a normal pregnancy and with no exposure to known teratogens. Labour, which was induced at term by rupture of membranes, lasted 9 hours. Fetal heart rate was normal during labour. Birthweight was $3.1 \mathrm{~kg}$, height $45 \mathrm{~cm}$, and head circumference $35 \mathrm{~cm}$. The infant appeared well at birth and had normal Apgar scores. About 4 hours later, he was noted to have an irregular heart rate and appeared dusky after a feeding. Signs of respiratory distress and a very abnormal electrocardiogram prompted transfer to The Hospital for Sick Children.

On arrival here, at 6 hours of age, the infant was acyanotic, but lethargic. The pulse was irregular, and its rate varied from 50 to $200 / \mathrm{min}$; the respiratory rate was $62 / \mathrm{min}$, temperature was $37^{\circ} \mathrm{C}$, blood pressure was $64 \mathrm{mmHg}$ in both arms and $72 \mathrm{mmHg}$ in both legs. Pulses were strong in all limbs except during tachycardia. The chest was clear and heart sounds were normal. A soft systolic ejection murmur was heard over the left sternal border. There was no cranial bruit. The liver edge was palpated $1 \mathrm{~cm}$ below the right costal margin.

A radiograph showed distinct enlargement of the heart, normal pulmonary vascularity, and a left aortic arch. The electrocardiogram showed complete heart block with ventricular ectopic beats giving rise to paroxysms of ventricular tachycardia (Fig. 1, 2, and 3). Echocardiography revealed normal anatomy, though the arrhythmia made interpretation difficult. Blood gases (in room air) were: $\mathrm{pH} 7 \cdot 33, \mathrm{~Pa}_{\mathrm{O}_{2}} 56$ and $\mathrm{PaCO}_{2} 27 \mathrm{mmHg}$; bicarbonate $14 \mathrm{mmol} / \mathrm{l}$. Biochemical and haematological blood values were normal, including serum electrolytes and calcium, blood urea nitrogen and glucose, and platelet and leucocyte counts.

Attempts to control the irregular rhythm with $0.1 \mathrm{mg}$ atropine followed by $3 \mathrm{mg}$ lignocaine intravenously were unsuccessful. We therefore undertook cardiac catheterisation, with a view to inserting a transvenous pacemaker. Pressure determinations were as follows ( $\mathrm{mmHg})$ : right atrial mean, 16; right ventricular, $80 / 18$; left atrial mean, 22; and left ventricle, $80 / 22 \mathrm{mmHg}$. $\mathrm{O}_{2}$ saturation in the left ventricle was 100 per cent. Biplane cineangiograms of the ventricles (the left was entered through a patent foramen ovale) showed biventricular enlargement, with an accentuated trabecular pattern caused by hypertrophy. Both ventricles contracted very poorly. There were no filling defects in any chamber. The ventricular septum was intact, and all valves appeared normal. The main pulmonary artery was slightly dilated. 


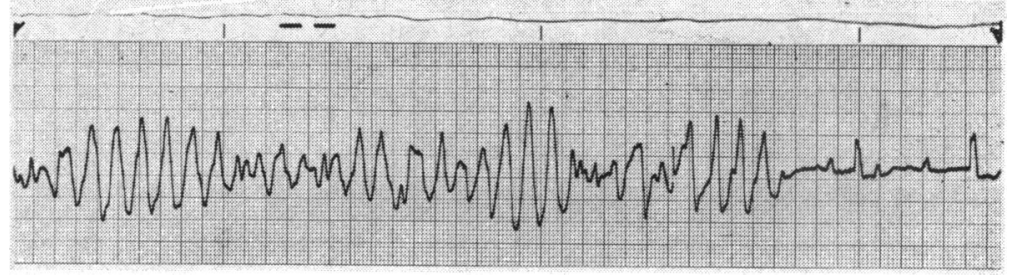

Fig. 1 Electrocardiogram showing 'torsade de pointes' and spontaneous conversion to slow ventricular rhythm. Lead II.

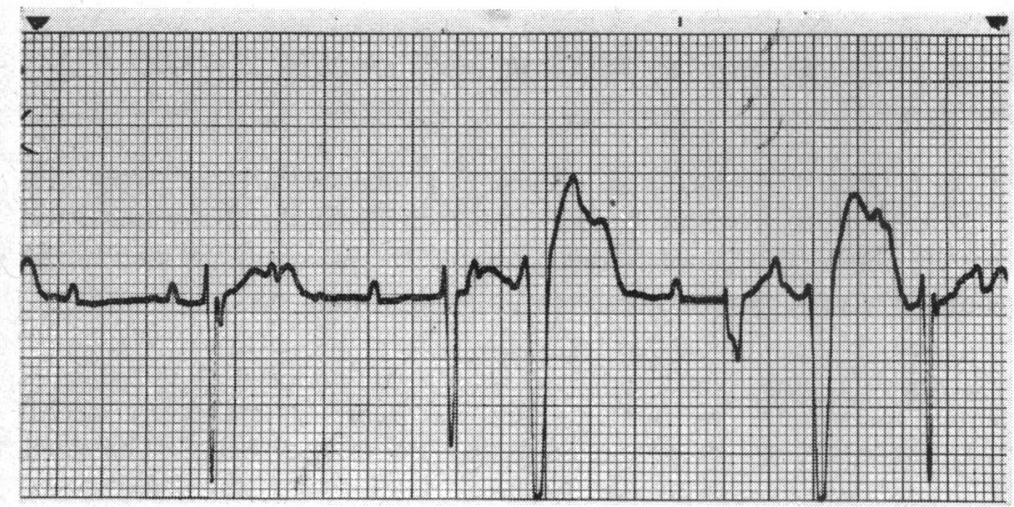

Fig. 2 Electrocardiogram showing complete heart block, ventricular premature beats, and slow ventricular rhythm. Lead II.

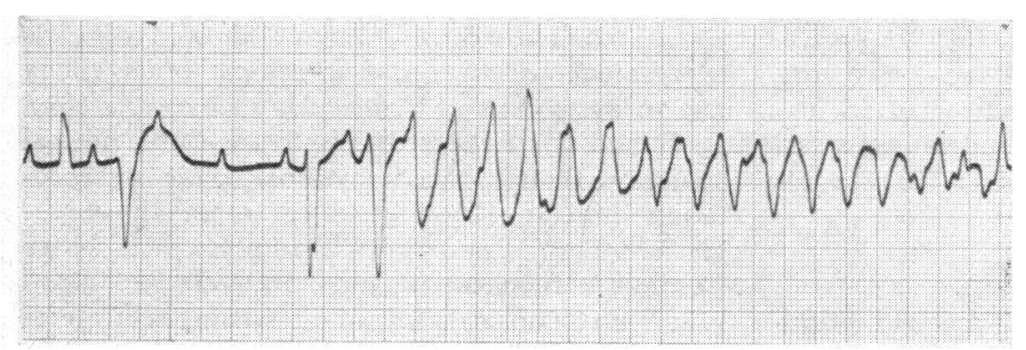

Fig. 3 Electrocardiogram showing onset of ventricular tachycardia with a late ventricular premature beat. Lead II.

Throughout the procedure, the infant had intermittent ventricular tachycardia and fibrillation, requiring repeated countershocks. Finally, a pacing catheter was installed via the long saphenous vein, with the tip at the apex of the right ventricle. Effective pacing was established initially, but the arrhythmia recurred very soon.

A continuous infusion of $20 \mu \mathrm{g}$ lignocaine $/ \mathrm{kg}$ bodyweight per min was begun immediately after catheterisation, but despite continual pacing and correction of acidosis, the irregular rhythm persisted. The injection of $10 \mathrm{mg}$ diphenylhydantoin intravenously and $6 \mathrm{mg}$ procainamide, doubling the lignocaine infusion rate, and increasing the pacing voltage, made no difference. Cardioversion at 20 joules was unsuccessful. Because of the development of congestive failure, the infant was digitalised and given frusemide intravenously, but these measures had no effect. The infant's deteriorating course was punctuated by seizures, apnoea, and 2 cardiac arrests, the second being fatal. Death occurred at $\mathbf{4 0}$ hours of age.

Necropsy revealed dilatation of the heart, which was anatomically normal, but double the normal weight for the infant's age and weight; the myocardium was pale and mottled. Histology showed myocytolysis, fragmentation of myofibrils, cellular oedema, and scanty lymphocytic infiltration. Viral cultures of myocardial tissue grew Coxsackie B3, but electron microscopy and cell cultures of nasopharyngeal and stool swabs were negative for virus particles. 


\section{Discussion}

Minor arrhythmias are common in the newborn, especially the premature infant (Church et al., 1967), but major rhythm disturbances at this time are rare. Specifically, supraventricular tachycardias, while common in children, are seldom reported immediately after birth, though Radford et al. (1976) have suggested that these may occur more frequently than they are recognised. Ventricular tachycardia has rarely been documented in infants and is similarly uncommon in childhood (Palaganas et al., 1965; Anthony et al., 1966; Van der Hauwaert, 1971).

An unusual feature of the tachycardia in this infant was the periodic change of QRS axis. This form of ventricular tachycardia, known as torsade de pointes, was recently reviewed by Krikler and Curry (1976). There have been few reports of its occurrence in children, and to our knowledge, this is the first report of this arrhythmia in a newborn infant.

What does appear evident from the few reported cases of ventricular tachycardia in children is the frequent association with other abnormalities, including congenital heart disease, diphtheria, skull fracture, cardiac tumour, upper respiratory tract illness, digitalis toxicity, and metabolic abnormality (Palaganas et al., 1965). There are also at least 8 reported cases with no apparent abnormality (Palaganas et al., 1965; Hernandez et al., 1975). Reports of ventricular tachycardia in neonates, also, indicate an association with congenital heart disease (Anthony et al., 1966; DeGuzman and Silver, 1970), metabolic abnormality-hyperkalaemia secondary to adrenogenital syndrome (Addy and Littlewood, 1969), and cardiac tumour (Van der Hauwaert, 1971). At least one idiopathic case has been reported (Hernandez et al., 1975), and in one the diagnosis was made in utero (Eibschitz et al., 1975). In our patient, all such conditions were ruled out by cardiac catheterisation and other laboratory tests. Though a possible association with myocarditis has been suggested (Hernandez et al., 1975), the rarity of this combination is supported by our experience: several neonates with myocarditis are seen in our institution each year, but a search through the records of the past 18 years revealed no case of ventricular tachycardia in a neonate.

The cause of ventricular tachycardia in neonates without associated underlying disease is a matter of speculation. 'Autonomic immaturity', suggested by Church et al. (1967) as the cause of the frequent minor arrhythmias in premature infants, may render term neonates especially susceptible to more major arrhythmias, particularly with an additional abnormality such as cyanotic heart disease, disordered metabolism, or myocarditis. Eibschitz et al. (1975) raise an intriguing possibility in connection with their case of intrauterine ventricular tachycardia. They postulated that over-production of adrenaline by the mother may have been responsible, a concept supported by disappearance of the ventricular tachycardia in the fetus after propranolol was given to the mother.

Treatment of the arrhythmia in our patient encompassed most of the standard pharmacological and electrical modes, with uniform lack of success. We tried to (1) control the bradycardia with atropine, (2) decrease automaticity with lignocaine, (3) prolong repolarisation and slow the ventricular rate with procainamide and diphenylhydantoin, and (4) control the ventricular rate with a transvenous pacemaker. Torsade de pointes is characterised by prolonged repolarisation, and it is aggravated by the quinidine-like agents appropriate for classical ventricular tachycardia.

Isoprenaline was not tried, but we expected pacing to stabilise the rhythm. We can only suggest that the cellular disturbance of the myocarditis was so profound that none of the usual treatments could overcome the arrhythmia.

We thank Dr Hartley Garfield for referring this patient to us, and Dr M. R. Dische for reviewing the histological specimens.

\section{References}

Addy, D., and Littlewood, J. (1969). Ventricular tachycardia associated with hyperkalemia. American Fournal of Diseases of Children, 117, 706-709.

Anthony, C. L., Stuart, L. D., Plunket, D. C., and Czarnecki, S. W. (1966). Ventricular tachycardia in infancy. American Fournal of Diseases of Children, 112, 469-475.

Church, S. C., Morgan, B. C., Oliver, T. K., Jr., and Guntheroth, W. G. (1967). Cardiac arrhythmias in premature infants: an indication of autonomic immaturity? Fournal of Pediatrics, 71, 542-546.

DeGuzman, A., and Silver, W. (1970). Ventricular tachycardia and transposition of the great arteries. Occurrence in an infant one hour of age and favorable response to septostomy. American Fournal of Diseases of Children, 119, 278-279.

Eibschitz, I., Abinader, E. G., Klein, A., and Sharf, M. (1975). Intrauterine diagnosis and control of fetal ventricular arrhythmia during labor. American fournal of Obstetrics and Gynecology, 122, 597-600.

Hernandez, A., Strauss, A., Kleiger, R. E., and Goldring, D. (1975). Idiopathic paroxysmal ventricular tachycardia in infants and children. Fournal of Pediatrics, 86, 182-188.

Krikler, D. M., and Curry, P. V. L. (1976). Torsade de pointes, an atypical ventricular tachycardia. British Heart fournal, 38, 117-120.

Palaganas, M. C., Jr., Fay, J. E., and Delahaye, D. J. (1965). Paroxysmal ventricular tachycardia in childhood. Keport 
of a case and review of the literature. Fournal of Pediatrics, 67, 784-791.

Radford, D. J., Izukawa, T., and Rowe, R. D. (1976). Congenital paroxysmal atrial tachycardia. Archives of Disease in Childhood, 51, 613-617.

Van der Hauwaert, L. G. (1971). Cardiac tumours in infancy and childhood. British Heart fournal, 33, 125-132.

Requests for reprints to Dr. John P. Finley, Department of Paediatrics, The Hospital for Sick Children, 555 University Avenue, Toronto, Ontario, Canada M5G 1 X8. 